gained by adding the pigment to the moulding composition. A considerable amount of research has been necessary to develop a luminous pigment sufficiently stable to withstand the stringent conditions of moulding, while at the same time care had to be taken that the pigment in no way affected the chemical stability of the plastic mass. Very considerable progress has recently been made in this direction.

An interesting range of moulded luminous plastics which appeal both to the domestic user and to A.R.P. authorities is manufactured by Roanoid, Ltd., of Glasgow. These are produced in a suitable lightcoloured thermo-setting plastic and include moulded letters and numerals in $1 \frac{1}{4}$ in. and 2 in. sizes, and also various fittings. Cellulose acetate sheet containing a variety of fluorescent dye-stuffs in standard sheets of $56 \mathrm{in}$. by $26 \mathrm{in}$. which can easily be cut or stamped to form displays or printed signs for shop windows, cinemas and theatres are available. The ultra-violet light used for irradiation of the plastic sheet is not harmful to the eyes, since the special 'blacklamps' of 80 and 125 watts used emit radiations which have no physiological action. It is stated that while fluorescent paints lose some of their power after a few weeks exposure, fluorescent plastic sheet showed no diminution during the period under test.

\section{Examination of Jewels in Electric Meters}

THE apparatus required to measure electric power is both expensive and requires special attention. The higher the accuracy aimed at the greater is the cost of the meter, and the time and labour that has to be devoted to it rapidly increases with the accuracy demanded. To encourage the use of electricity, the Electricity Commissioners have recently allowed the testing for low-load performance to be done at one tenth instead of one twentieth of full-load capacity. Another economy they have effected is to show that an appreciable extension of the life of jewels and pivots of electric meters can often be obtained by cleaning. An article on meter jewels, their examination, grading and reconditioning, giving the recommendations by the Meter Technical Committee of the Electricity Commissioners for overcoming the present difficulties of obtaining new jewels and pivots, appears in the Electrical Review of August 8.

The first method deseribed is to use a microseope with a magnification of 40-70 diameters, the stage being fitted with a simple means of holding the jewels, coaxially with the microscope and automatically positioned with the jewel cup in focus. The chief defects to be looked for are surface cracks, appearing as sharply defined straight or curved lines (parallel if more than one) on the jewel surface, and scratches from the original polishing or acquired during transport. Jewels, after examination, are classified Grade I jewels, which can be- used immediately; Grade 2, which can be re-surfaced, showing no defects beyond shallow central wear or slight scratches within the working surface area. A pivot end that is unpolished and of bad shape must be ground to shape and polished; it should be hemispherical and never ground to a needle point. Even very slight films of dust or grease may obscure serious defects. Boiling in an aqueous solution of sodium hydroxide followed by quick drying and a rinse in commercial alcohol is said to be beneficial.

\section{The Solar Corona}

Dr. Donald H. Menzer has an article entitled "What is the Solar Corona?" in the Telescope of MayJune, in which he refers specially to the researches of Bengt Edlén, of Uppsala, who has shown that coronium is chiefly iron. Nickel and calcium have also bren identified, the outer electrons in all these elements being torn away. Difficulties arise in explaining how the comparatively low temperature of the sun-about $6,000^{\circ}$ C.-can be responsible for tearing away the outer electrons, the removal of which requires a temperature of at least $100,000^{\circ} \mathrm{C}$. Then again, Edlén has pointed out that the great breadth of the coronal lines suggests a very rapid movement of the atoms, and a temperature of $2,000,000^{\circ} \mathrm{C}$. would be required to explain this. Conclusions of a similar nature have been reached by independent lines of investigation and various explanations have been suggested to account for the source of this high temperature. The most acceptable hypothesis is that the highly heated coronal matter is issuing in great jets from holes and cracks in the solar surface. These crevices, which are probably associated with sunspots, run far down into the hot interior, where the temperature is several million degrees.

Many problems arise as a consequence of this hypothesis. Thus it is suggested that solar promin. ences are formed as condensations from the corona, and the motion-picture records of active prominences corroborate this view. Thousands of miles above the solar surface prominences are observed to "materialize" and to be moving downwards. They are previously invisible because their earlier high temperatures caused them to emit radiations of an unfamiliar character. The identification of the remaining coronal lines still awaits a solution and a great mystery is the tendency of coronal matter to move in well-defined arches or streamers. A possible explanation may be found in the presence of magnetic and electric fields. It is suggested that the source of electrification of the ionosphere may be found in the $\mathrm{X}$-ray energy associated with the coronal emission.

\section{Forest Administration in Malaya}

THE annual report of the Malay Forest Department for the year 1939 (Govt. Press, Kuala Lumpur, Federated Malay States, 1940) is of unusual interest. A history is given of the growth of the Department from the year 1883, when the Director of Gardens, Straits Settlement, initiated a. small Department. Five years later, Mr. H. N. Ridley became director and instituted a policy of Government reservation which saved valuable forests from destruction during the rubber boom of thirty years ago. As the result 
of a report on the forests by the late Mr. H. C. Hill of the India Forest Service, a Burma forest officer was appointed to the control. At present, the ten States of Malaya have each a Forest Department loosely united by a common and interchangeable staff of senior European officers and an ever-increasing body of Malays trained in the vernacular school of Kepong.

In some respects the Malay States now possess one of the most up-to-date forest departments in the Empire. That this is realized by the Government is evidenced by the recent investigation into the position of forestry and mining. Mining is one of the most important of the industries and yet the interests of the mining community tend to elash with those of agriculture and forestry. Some 10,471 square miles of the States are reserved forest (about 20 per cent of the country), yet 52.8 per cent of forest land still remains unaccounted for. Much of the reserved forest is in mountainous country. The mines are mostly concentrated in the plains. Since timber is heavy and will not bear expensive transport charges, the Forest Department wishes to develop the management of the forests which are reasonably accessible-often in the neighbourhood of existing mining tracts and into which the mining industry may wish to expand. It is recognized that the mining community takes a large amount of the produce of the forests. The problem which is now being faced is to settle, if possible for a period of years, those areas which will probably be required for the extension of mining. In this the Geological Department is affording assistance; thus allowing the Forestry Department to concentrate its works of improvement on workable, because accessible, forests which will not be liable to be expropriated. at short notice. The crucial point arising out of the arrangement is the obvious recognition by the Government of Malaya of the importance of the forests to the country and its inhabitants.

\section{Venereal Diseases in War}

According to M. Schubert (Ven. Dis. Inform., $22,327 ; 1941)$, a comparison between the incidence of venereal diseases in the Prussian Army during 1903-1913 and the four years of the War of 1914-18 showed that the average incidence was $20 \cdot 4$ per 1,000 during peace-time and 20.5 per 1,000 during the War. Contrary, therefore, to the widely prevalent but false assumption that the incidence of venereal diseases during that War was much higher than in peace, the difference was only very slight. The only increase which did occur was in the number of cases of syphilis. Of those infected during the War 67.5 per cent contracted their infection at home and only $32 \cdot 5$ per cent at the front. After demobilization of the army after the War there was a catastrophic increase in the incidence of venereal disease up to 1921-22, after which date there was a gradual decrease which in 1925-26 became increasingly noticeable and was probably due to better-regulated conditions for treatment. The decrease in the incidence of syphilis was greater than that of gonorrhœa. During the past few years chancroid has been very rarely seen in Germany. During the first nine months of the present War no increase in the incidence of venereal disease has been observed except among the troops who had been in Poland, in whom the number of syphilitic infections was low and chancroid was not found.

\section{Health of Hong Kong}

According to Dr. Selwyn Clarke, the director of medical services, Hong Kong, in his annual report for 1939, the colony's chief health problem is the large number of Chinese refugees from the SinoJapanese War. In July 1939 the number of persons entering the colony exceeded the number leaving it by 327,833 . Many of the immigrants were destitute, ill-nourished and diseased, and the overcrowded conditions in which they lived were a most serious menace to public health. The largest number of deaths in 1939 were caused by non-tuberculous diseases of the respiratory system. Tuberculosis came next, the majority of the deaths being due to the pulmonary form. 24 per cent of 1,500 refugees whose blood was examined showed a malarial infection. There were more than 9,000 cases of beriberi, 800 cases of cholera and 3,000 of influenza during the year.

\section{Announcements}

A Rockefeller Foundation grant of 25,000 dollars for research in endocrinology for five years under the direction of Dr. J. S. L. Browne, assistant professor of medicine and lecturer in pathological chemistry at McGill University, is among recent gifts to the University.

A Department of Radiology has recently been established in the medical faculty at McGill University under the direction of Dr. C. L. Peirce, radiologistin-chief at the Royal Victoria Hospital, and Dr. W. L. Ritchie, director of radiology at the Montreal General Hospital.

THE National Institute of Health of the United States Public Health Service is organizing a new research unit to be called the "Unit of Gerontology", which will deal with the diseases of the aged. Further information can be obtained from Dr. Edward J. Stieglitz, Investigations in Gerontology, National Institute of Health, United States Public Health Service, Bethesda, Maryland.

ON the recommendation of the Agricultural Research Council, the following awards of one agricultural research scholarship and two studentships for research in animal health have been made by the Ministry of Agriculture and Fisheries, and the Department of Agriculture for Scotland: H. E. Davenport, of University College, Nottingham, a research scholarship in helminthology; F. Alexander, of the Royal (Dick) Veterinary College, Edinburgh, a studentship for research in animal health; A. McDiarmid, of the Royal (Dick) Veterinary college, Edinburgh, a studentship for research in animal health. 